\title{
Confusion about form and function clouds launch of EC's Decade of the Brain
}

\begin{abstract}
Munich. Hopes for a cohesive European programme for neuroscience research hang in the balance this week as the European Commission (EC) launches its 'Decade of the Brain'. The early launch — before the programme has been approved by EC member states and before any financial commitments exist - has taken many by surprise, and its unveiling at a specialized meeting on depression has added to the confusion about its general aims.
\end{abstract}

The initiative follows several failed attempts by the 2,500-member European Neuroscience Association (ENA) to persuade the EC to match the Human Frontier Science Program, begun by the Japanese in 1989 and now international, and the US Decade of the Brain, launched in the same year. Last year, however, EC research commissioner Filippo Pandolfi took up the cause and in February 1992 he appointed a task force of experts from member states to analyse the needs of European neuroscience.

By early summer, the task force had developed a detailed four-part proposal, costing ECU100 million (US\$140 million) a year. Each part of the proposal conforms to the normal structure for EC research funding. A 'networking' section proposes the establishment and funding of projects carried out in several laboratories in different countries. Expansion of existing high-cost research facilities such as PET scanners and primate houses is suggested to allow sharing of services between member countries. A training section provides for postdoctoral fellowships, summer courses and the funding of pan-European meetings.

Some 70 per cent of the funds would be destined for joint collaborations between universities and industry, particularly the pharmaceutical industry which has been criticized for investing less in research than do US drug companies. Costs would be shared equally by the $\mathrm{EC}$ and industry.

The fate of the proposal rests with the EC's next five-year plan, known as the fourth Framework, which begins in 1994. Although the Framework's structure is still under discussion, the European parliament, which acts independently of the commission, passed a resolution in July recommending that the commission establish "a specific research programme in neurosciences within the next framework programme".

There is concern, however, that the EC's enthusiasm for the idea may have cooled. Michel André of the EC's research division says that neuroscience is "very unlikely" to be accepted as a core theme of the next fiveyear funding plan. "We can only propose realistic things", he says. "There are lots of topics in Framework, not just neuroscience - although the commission does think it is a very important subject."

An alternative to a separate programme is an 'umbrella group' that would oversee neuroscience-orientated projects funded within such broader themes as biomedical research and the human mobility programme to promote networking. The group would eliminate redundancy among projects and merge some programmes. André says that this would allow European research to reach a critical mass that has been lacking despite the estimated 12,000 neuroscientists throughout Europe. Under such a system, neuroscience projects would continue to compete for funds against other research disciplines within each general theme.

Members of the task force are unhappy with the idea of an umbrella group rather than a separate theme, arguing that neuroscience warrants a distinct budget and that the Decade of the Brain would be weak- ened without it. Scientists at last week's meeting of the European Neuroscience Association (ENA) seemed to support the idea of a Decade of the Brain but were confused about what it entailed and its appearance at the end of a small clinical neuropharmacology meeting. EC officials say that the decision to launch the initiative was made in April, after the programmes of the larger pan-European meetings, such as the ENA, had been fixed. And a Brussels-based meeting was preferred to make possible a royal endorsement, in this case by the Queen of Belgium.

Final decisions about how the European Decade of the Brain will be managed and financed are expected within the next couple of months after the overall Framework plans have been completed. In the meantime, lobbying and arguments will continue in an attempt to avoid criticism, widespread in the United States, that such an initiative is likely to involve more rhetoric than new money.

Alison Abbott

\section{Crossing the border, crossing the ocean}

Munich. The European Neuroscience Association (ENA) must undergo radical change to meet its goal of raising the quality of pan-European research to the level of that in the United States, according to scientists at last week's annual ENA congress in Munich, which was attended by only 1,700 .

Although Europe has a strong base in neuroscience, it is confined to individua countries and fails to reach the 'critical mass' needed to carry out research most efficiently. Scientists and policy-makers say this isolation is the reason Europe trails behind the United States, and that ENA's efforts to increase cooperation among Europe's estimated 12,000 neuroscientists do not match the success of the US Society for Neuroscience.

The US society's annual meeting regularly attracts at least 15,000 participants, including several thousand Europeans who prefer to cross the Atlantic than to attend the ENA. Part of the reason is cost - it can be cheaper to fly to the United States than within Europe, and registration fees are lower. The US meeting has an additional, nonmonetary advantage: it has become a global bazaar for making professional contacts.

In spite of apathy towards the ENA, Europeans still attend their own national conferences in droves. By fulfilling the needs of young postdoctoral researchers to meet prospective employers among their own scientific community, France's Societé de Neurosciences and Germany's Neurobiologen-tagung, for example, attract 1,000 or so scientists for meetings in their native language. According to Walter Zieglgänsberger, who organized the Munich meeting, the barrier that ENA must cross is more cultural than linguistic. "People still don't think European", he says, "but in America, they think American".

The ENA also wants to lower the cost of its meetings by replacing professional organizers with local ones and by seeking corporate and philanthropic contributions. Much hope is pinned on the European Commission's plans to support pan-European neuroscience, under the 'Decade of the Brain' initiative. Although not yet accepted by the Commission, many expect this to be the most likely source of the ENA's salvation.

The ENA also realizes that it may need to change its own organizational structure. The association may work more effectively as a federation of successful national societies, most of which want to maintain their own identities, rather than as an organization that chooses its leaders without regard for nationality. 